\title{
LEITURAS DO PODER NA TERCEIRA ERA DA TERRA-MÉDIA: UM ENSAIO BASEADO EM 0 SENHOR DOS ANÉIS
}

- Rafael da Silva Nunes *

Resumo: 0 imaginário se estabelece como um campo fértil para o pensamento das múltiplas relações existentes e experienciadas pela realidade humana. Questões associadas à discussão socioeconômica, física, biótica, política, entre outras, podem ser exploradas a partir de construções que possuem, por base, a imaginação. Neste caso, a literatura surge como um dos instrumentos de representação de realidades (des)conhecidas passíveis de serem lidas sob as múltiplas óticas supracitadas. A obra de J. R. R. Tolkien intitulada de "O Senhor dos Anéis" se apresenta como um arquétipo de uma imaginação complexa na qual diferentes sociedades são apresentadas, relacionando-se interna e externamente de múltiplas maneiras. A obra, a partir da sua própria complexidade, apresenta-se como um excelente palco para o desenvolvimento de inúmeros ensaios sobre diferentes esferas que envolvem a própria percepção humana da realidade. Uma das esferas mais discutidas na obra de Tolkien refere-se à dinâmica do poder que pode ser observado na política entre as múltiplas sociedades existentes na Terra-Média. Neste sentido, o objetivo do presente estudo é analisar, a partir dessa obra, como o poder é encarado por seus múltiplos personagens (e sociedades), bem como compreender que dinâmica possibilitou o surgimento do poder político na Terra-Média.

Palavras-chave: Senhor dos Anéis, poder, política, soberania

\section{1 - Introdução}

A arte literária fulgura como uma das principais formas de representação de realidades (ficcionais ou não) da percepção humana sobre a sua própria condição de existência. Expressa uma série de aspirações, conflitos, dilemas e dúvidas em relação à 
construção do ethos humano, e mais especificadamente, do ethos de sociedades particulares. O imaginário é construído e reconstruído a cada momento possibilitando o surgimento de "novas" ideias que contribuirão sobremaneira para, mais uma vez, moldar a própria experiência humana.

A arte literária (ficcional ou não) expressa o reflexo (ou projeção) da história e das realidades sociais, permitindo desta maneira que se retratem culturas e costumes, práticas e ações conhecidas, organizações políticas e sociais. Esta arte se apresenta como uma dimensão para as diversas relações socioeconômicas, ambientais e políticas, que estabelecem um paralelismo com a realidade, expressando e sendo expressa por um laço que une a realidade ao imaginário.

Uma cultura, afinal de contas, constitui uma espécie de sistema neurovegetativo que irriga, segundo seus entrelaçamentos, a vida real do imaginário, e o imaginário da vida real. Essa irrigação se efetua segundo o duplo movimento de projeção e de identificação... O imaginário é um sistema projetivo que se constitui no universo espectral e que permite a projeção e a identificação mágica religiosa ou estética. (MORIN, 1984, p. 81).

A saga desenvolvida por J. R. R. Tolkien pode ser vista como uma obra épica na qual a literatura serve como o meio pelo qual o universo criado é representado (ainda que inicialmente pelo fato de que, atualmente, existem outras tipologias de representação do referido universo como filmes, pinturas, entre outros). No entanto, é importante salientar que o próprio autor da obra expressava que seu objetivo não era desenvolver um mundo em si, mas sim criar um ambiente no qual as línguas que desenvolvera pudessem ser apresentadas e associadas a uma trama maior.

Para Tolkien, as "histórias" que inventou foram feitas para proporcionar um mundo às línguas que criara. Dizia que primeiro pensava num nome e depois vinha a "história”. A partir disso, após a difusão em outros idiomas, desenvolveu um guia de nomes para auxiliar os tradutores (...). Quando the perguntaram certa vez sobre o que era $\mathrm{O}$ Senhor dos Anéis, respondeu simplesmente: um ensaio de estética linguística. (GANDRA e FILHO, 2006, p. 39). 
Apesar de não ser seu objetivo primeiro, a obra elaborada ganhou profundidade em relação a outras obras de época na medida em que a saga é desenvolvida não apenas de maneira a correlacionar eventos associados à destruição do Um Anel, mas sim, à criação de um universo complexo no qual a sua própria mitologia é construída. Gandra e Filho (2006), por exemplo, expressam que o mundo criado por Tolkien refere-se à construção de uma mitologia inglesa que bebe diretamente de uma série de outras cosmologias do passado. Ao longo da obra "O mundo de o Senhor dos Anéis", os autores explicitam uma série de paralelismos com a mitologia nórdica e a cosmovisão cristã de mundo (muito influenciado pela própria origem católica do autor). Esta profundidade sobre o universo tolkiano se expressa de maneira tão marcante, que atualmente, cunha-se um termo para se referir ao estudo das suas obras relacionadas à Terra-Média: Tolkienologia.

Estas aproximações e paralelismos vão ao encontro das ideias expressas anteriormente: o imaginário é construído a partir das realidades conhecidas, e a realidade, por sua vez, passa a ser influenciada pelas construções elaboradas no campo da imaginação.

O Senhor dos Anéis estabelece-se como um verdadeiro ensaio humano sobre a diversidade social no seu sentido mais amplo. Cria e apresenta diferentes arquiteturas societárias, com diferentes anseios e ideais, bem como diferentes culturas, que transformam o recorte dos acontecimentos (a Terra-Média) em um ambiente complexo de relações que podem ser analisadas sob diversos aspectos. No entanto, e tendo por base uma leitura mais superficial da obra, deve-se destacar que as dinâmicas do poder são uma discussão central da obra já, que salienta a necessidade de combate dos povos livres contra a tirania de um agente que quer dominar a Terra-Média como um todo.

A seguir, será apresentada uma discussão sobre as formas de poder expressas no universo tolkiano, partindo-se inicialmente da ideia de que é impossível a formação do chamado "Estado Moderno" pela falta de coesão entre as diversas sociedades daquele lugar fantástico, bem como, a partir dos múltiplos tipos de poder estabelecidos no recorte analisado. Entretanto, apesar de tal inexistência, sugere-se a partir da formação do Conselho de Elrond (como será visto mais adiante), uma das primeiras tratativas políticas para a resolução de um problema comum aos povos livres. 
2 - A (Im)possibilidade da formação do estado moderno no universo tolkiano

A Terra-Média, construída e imaginada por Tolkien apresenta temporalidades sobrepostas que (re)organizam, continuadamente, o território a partir dos modelos políticos variados que se estabelecem em um mesmo espaço. Essas sobreposições indicam traços de "avanços" e "retrocessos" de sistemas políticos associados a diferentes organizações que contribuem para o entendimento (ou pelo menos a imaginação) da complexidade das relações ali apresentadas.

Quando se traça um paralelismo com a nossa sociedade, nos atemos inicialmente, ao entendimento daquilo que se entende por Estado Moderno. Conforme exposto por Font e Rúfi (2006), a formação desse Estado se baseia na transição da estrutura feudal para uma relação absoluta de poder, na qual se estabelecem novos vínculos entre diferentes grupos sociais que passam a assumir papéis distintos e sinergéticos na construção de uma nova instituição em definição. De acordo com os autores apresenta-se a necessidade de rompimento das barreiras comerciais impostas até então (pelas classes que emergem neste momento) e da tentativa de rompimento “da fragmentação política e territorial medieval” (FONT e RÚFI, 2006, p. 96).

Ou seja, o Estado por si só deve ser entendido como uma nomenclatura jurídica relacionada à soberania, aos territórios e aos cidadãos tomados por um todo (HABERMAS, 2000). No entanto, do ponto de vista sociológico, Habermas aponta que o que contribui para a formação do Estado Moderno, institucionalmente refere-se ao estabelecimento

de um aparelho administrativo legalmente constituído e altamente diferenciado, que monopoliza os meios legítimos da violência e obedece a uma interessante divisão do trabalho com uma sociedade de mercado que é livre no tocante às funções econômicas. (HABERMAS, 2000, p. 297)

Assim, o Estado deve ser observado por uma relação que alia relações de mercado com burocracia. Exatamente por estes fatores, é que se nota um afastamento do que é entendido como Estado Moderno no seu ínterim na Terra-Média. A construção da narrativa, a apresentação dos personagens (e às sociedades às quais eles pertencem), as sociedades e instrumentos de regulação sugerem uma série de tensões distintas atreladas à dinâmica territorial que impedem a utilização da tríade (soberania, território e cidadãos) apresentada por Habermas (2000). 
Além disso, salienta-se que ao longo das formações de Estado (e aí podemos utilizar a Idade Média como grande janela temporal que remete ao universo tolkiano), a língua e a hereditariedade (como será visto a seguir) são componentes centrais na formação dessas unidades territoriais nesta literatura fantástica. As nações eram formadas apenas por origens ancestrais comuns, pela localização geográfica e pela língua/raças formadoras desta mesma sociedade.

No caso clássico dos romanos, natio, tal qual como gens, funciona como o oposto de civitas. Nele, as nações são a princípio, comunidades de pessoas de ascendência comum, ainda não integradas na forma política do Estado, mas que se mantem unidas simplesmente por sua localização e por sua língua, costumes e tradições comuns. Essa utilização da palavra atravessa a Idade Média até o início da era moderna, aplicando-se a todas as situações em que natio e língua são consideradas equivalentes (HABERMAS, 2000, p. 298).

\begin{tabular}{|l|l|}
\hline \multicolumn{1}{|c|}{ Raças } & \multicolumn{1}{c|}{ Línguas } \\
\hline Elfos & Élfico (Quenya/ Sindarin) \\
\hline Humana & Homens (Mannish) \\
\hline Anões & Khuzdul / Iglishmêk \\
\hline Ents & Entiano \\
\hline Ainur (Valar e Maiar) & Valarin \\
\hline Orcs & Orquiano \\
\hline *Sauron (Maiar) & Língua Negra \\
\hline Wargs & Outras Línguas \\
\hline Aves & \\
\hline
\end{tabular}

Quadro 1: Raças e Línguas da Terra-Média

Fonte: Adaptado de TolkienGateway (s/d)

Habermas, inclusive aponta, no mesmo texto, que "ser membro de determinado Estado significava apenas estar submetido a suas autoridades" (HABERMAS, 2000, p. 301). Ora, a lógica de poder que ali se estabelecia e a privação do sentido de cidadania aos pertencentes daquelas sociedades, reforça ainda mais o quadro estabelecido, mantendo a estrutura social inalterada.

Apesar da "impossibilidade” da formação do Estado Moderno na era Tolkiana, e devido à importância que assume o papel da soberania das nações, torna-se fundamental, fazermos uma leitura de todos os jogos de poder associadas ao universo tolkiano. Estas estruturas, inclusive, contribuem para a manutenção de um quadro no 
qual se congelem as temporalidades "medievais", numa permanente (re)estruturação dos espaços e dos personagens/sociedades que ali se inserem. No entanto, há de se discutir como os entraves da formação do Estado Moderno repercute sobre as esferas de poder atreladas às múltiplas sociedades moldadas. Surge aí, a necessidade de se discutir como a soberania dos povos era encarada e estabelecida a partir de diferentes estratégias de articulação e coação.

\section{3 - Soberanos e poderes rousseaunianos e hobbesianos na Terra-Média}

A formação do contrato social, discutida por Claval (1978) apresenta-se como um dos principais marcos da criação do Estado Moderno, ou seja, a sua Institucionalização. Este contrato que servia como um dos instrumentos de formação deste Estado Moderno, no entanto, garantia diferentes pontos de vista acerca de sua construção: para alguns autores, como Hobbes, o Estado Absolutista apresentava-se como um modo de impor a convivência entre os formadores de determinada sociedade, ou seja, haveria a necessidade de regulação por parte de um poder central que aglutinaria a sociedade a partir de determinadas regras.

O soberano, neste caso, se impunha através de estratégia para amalgamar a sociedade em sua subordinação. Subordinação esta que seria responsável por dissolver parte da premissa de que homens só vivem em paz, uns com os outros, diante da concessão das liberdades individuais para um representante. Hampton (1995) apresenta que a condição materialista de Hobbes contribuía diretamente para o entendimento de que o fato psicológico do ser humano e sua formação enquanto ser se estabelecem como premissas da soberania absoluta definida pelo autor.

Já Rosseau, ao contrário, refutava tais premissas. O autor acreditava que o contrato era formado e constituído por um conjunto de ações puras em que os cidadãos estabeleceriam relações, ou seja, o pensador aspirava à construção de relações tecidas em um cenário de boa-vontade dos diversos componentes na sociedade (CLAVAL, 1978). Corresponde, portanto, à retomada de um ambiente no qual os homens viviam sem a necessidade da institucionalização de relações através de um governo. A autonomia dos povos corroboraria com a formatação de uma sociedade autônoma de si mesma, sem a necessidade de que se figurassem representatividades senão o próprio coletivo. Portanto, associa-se diretamente a visão de que a sociedade construída e idealizada por Rosseau concebe, inicialmente, a perduração da igualdade baseada nos 
laços morais que unem a todos os indivíduos partícipes da mesma e é justamente esta relação que permite a sobrevivência do próprio coletivo.

Surgem, a partir das considerações apresentadas, diferentes formas e correlações atreladas à dinâmica de como o poder é "produzido". Para Hobbes, trata-se da necessidade de mediação e controle da maldade e egoísmo humano. A função do soberano é definida a partir desta necessidade visando minimizar esta distorção social, ao passo que para Rousseau a premissa é de que o homem não possui tal característica (egoísta e maléfica). No entanto, a prática da espontaneidade das relações (autocracias) contribuem para que os indivíduos, tratados aí como iguais, se autorregulem.

Rosseau acredita piamente que a utilização da força como estratégia de dominação é imoral, e desta forma, deve ser encarada como um ato de injustiça, caracterizando por sua vez que o contrato social deva ser baseado não no terror e sim na vontade geral, expressando aí seu desejo de que se estabeleça a democracia entre os participantes de dada sociedade. Nas palavras do autor, "a força é um poder físico; não imagino que moralidade possa resultar de seus efeitos. Ceder à força constitui ato de necessidade, não de vontade; quando muito, ato de prudência” (ROSSEAU, 1973).

No outro front de ideias, Claval (1978) apresenta que,

Hobbes é um teórico de um sistema político em que o poder a autoridade não tem nenhuma limitação: quaisquer que sejam seus erros e as exações do soberano, a ordem que ele assegura é superior à desordem do Estado natural. (...) Não tem a complexidade das pirâmides e regras e o prestígio das sociedades de ordens: comporta apenas dois estágios, o da autoridade e o da massa que lhe está submissa. (CLAVAL, 1978, p. 131).

Verifica-se, portanto, que a construção das relações deveria se apresentar e se estruturar de maneira diferenciada para os dois autores. Hobbes defende que o contrato social transfere os direitos e autoridade para o soberano, tornando-o a figura central da perspectiva do planejamento territorial. Transferem assim a autoridade coletiva para um representante individual (ainda que esta transferência, como já comentado anteriormente, parta da vontade ou da coação). Para o outro, esta prática configura a perda da democracia, uma vez que não há, passada a autoridade coletiva para a autoridade individual, capacidade de se estabelecer a democracia plena ${ }^{2}$.

Daí, quando avaliamos o cenário apresentado e construído ao longo da trilogia "O Senhor dos Anéis", verifica-se uma série de exemplos capazes de contribuir para comportamentos distintos sobra a leitura da formação (ou forja) do Contrato Social. 
Podemos aqui conceber, inicialmente, os chamados "Povos Livres" da Terra-Média (todos aqueles que não se encontravam sobre as garras e dominações de Sauron, Senhor das Sombras), sendo representados por raças como Elfos, Homens, Hobbits e Anões por exemplo. Cada um destes povos possuíam arquiteturas organizacionais distintas que ora se assemelhavam com a adoção de um soberano (seja por aclamação ou hereditariedade) e, portanto, com a perspectiva hobbesiana, ora por relações sociais espontâneas que corroboravam para a construção de uma sociedade baseada na sinergia cidadã (caso dos Hobbits do Condado, por exemplo) e, portanto, com uma perspectiva roussoniana.

Mordor, por sua vez, resplandece como um exemplo nítido no qual Sauron, soberano explorado através da trilogia dos livros, incorpora em si mesmo a autoridade, sendo a massa de seus súditos forjada a partir de diferentes elementos constituintes dos territórios dominados ou ainda através da apropriação dos jogos de influência que se estabeleciam diretamente a partir da cooptação/corrupção. O poder despótico, arbitrário e centralizado (WEBER, 1982) apresenta-se como uma estrutura forjada para a manutenção e espraiamento territorial de Mordor. Há que se destacar aqui que não era incomum a utilização de técnicas variadas de tortura para a obtenção de informações que possibilitassem o acesso a informações garantidoras, por sua vez, o aumento do poder, como representado na passagem a seguir ${ }^{3}$.

O que Gollum estivera fazendo não dizia. Apenas chorava e nos chamava de cruéis, com muitos gollums de sua garganta: e quando o pressionamos, lamentou-se e nos adulou, e esfregou as longas mãos, lambendo os dedos como se doessem, como se estivesse lembrando de alguma tortura antiga" (TOLKIEN, 2000, p.60).

Ramos (2013), ao fazer uma leitura sobre o sistema de poder saurônico na Terra-Média, desenvolve uma discussão baseada em duas diferentes formas de poder a partir dos ensinamentos de Foucault (COLOMBO, 2011). Apresenta dois poderes fundamentais aos quais chama de:

1) Poder da Soberania: relacionado àquilo que se entende como poder prémoderno

2) Poder disciplinar: baseado fundamentalmente na perspectiva da disciplina e da vigilância (moderno). 
O Poder Pré-Moderno (primeiro poder), de acordo com o autor, relaciona-se diretamente à capacidade da visibilidade do soberano diante da terra ou campo observado, permitindo-se desta maneira a implementação de castigos que corroboram para a manutenção do seu poder legitimado pelo medo e pavor. Este poder (soberano) é apresentado por Ramos (2013) a partir da leitura de três exemplos básicos de como este se estabelece, como pode ser visualizado no quadro resumo a seguir.

\begin{tabular}{|l|l|l|l|}
\hline \multicolumn{1}{|c|}{ Tipo } & Personagem & \multicolumn{1}{c|}{ Forma de Manutenção } & \multicolumn{1}{c|}{ Súditos } \\
\hline \multirow{2}{*}{$\begin{array}{l}\text { Poder } \\
\text { Soberano } \\
\text { (Pré- } \\
\text { moderno) }\end{array}$} & Rei Theoden & Laços de sangue/hereditariedade & Reino de Rohan \\
\cline { 2 - 4 } & Saruman & $\begin{array}{l}\text { Política (Agente duplo na relação } \\
\text { com Sauron e Povos Livres) }\end{array}$ & $\begin{array}{l}\text { Maiar e Exército de } \\
\text { Isengard }\end{array}$ \\
\cline { 2 - 4 } & Sauron & Servo e comandante de Morgoth & $\begin{array}{l}\text { Limites de Mordor e } \\
\text { Influentes }\end{array}$ \\
\hline
\end{tabular}

Quadro 2: Personagens associados ao Poder Soberano

Fonte: Adaptado de Ramos (2013).

É interessante, no entanto, que se explicitem algumas diferenças quanto a percepção do quadro apresentado. Discordo aqui da acepção apresentada por Ramos (2013) de que o Poder Soberano é plenamente experenciado nos exemplos citados, tendo em vista que a soberania exercida pelo Rei Theoden ${ }^{4}$ não se satisfaz completamente, ou seja, seja por hipnose/controle, seja por corrupção, ainda não possuem autonomia capaz de garantir a sua própria soberania. Seriam, neste caso, "falsos soberanos" já que possuem suas relações de poder circunscritas apenas àqueles relacionados ao hipotético domínio territorial, mas são subjugados a outras dimensões/forças hierárquicas que se estabelecem na Terra-Média.

O caso de Saruman é um tanto mais complexo, pois o mesmo, apesar de ser apresentado como soberano (dos Maiar e do Exército de Isengard), busca através dos entrelaces políticos atuar como parceiro das operações pensadas pelo Conselho de Elrond e ao mesmo tempo de Sauron, visando garantir o poder para si. Ou seja, utilizase do campo político para a partir de múltiplos acordamentos, garantir o poder para si, tornando-se um agente duplo, mas que busca a soberania diante dos demais. Inclusive, Saruman, ao ser cercado por parte da então já debilitada Companhia do Anel, propõe, em último ato, firmar uma parceria com Gandalf para que juntos combatam o poder 
que se levanta de Mordor, ainda que vislumbrando o poder para si com o controle do Um Anel.

Um novo Poder se levanta. Contra ele, as velhas alianças e políticas não nos ajudarão em nada. Não há mais esperança nos elfos ou na agonizante Númenor. Esta então é uma escolha diante de você, diante de nós. Podemos nos unir a esse Poder. Seria uma sábia decisão, Gandalf. Existe esperança por esse caminho. A vitória dele se aproxima, e haverá grandes recompensas para aqueles que o ajudarem. Enquanto o Poder crescer, os que se mostrarem seus amigos também crescerão; e os Sábios, como você e eu, poderão, com paciência, vir finalmente a governar seus rumos, e a controlá-lo. Podemos esperar nossa hora, podemos guardar o que pensamos em nossos corações, talvez deplorando as maldades feitas incidentalmente, mas aprovando o propósito final e mais alto: Conhecimento, Liderança, Ordem; todas as coisas que até agora lutamos em vão para conseguir, mais atrapalhados que ajudados por nossos amigos fracos e inúteis. Não precisaria haver, e não haveria, qualquer mudança em nossos propósitos, só em nossos meios (TOLKIEN, 2000, p.269).

Ou seja, verifica-se nestes exemplos uma hierarquia de poder relacional entre eles, descaracterizando o chamado de poder soberano individual e autônomo. Isto não quer dizer, no entanto, que não existam outras soberanias na Terra-Média. Diferentes povos, com diferentes estruturas de poder se estabelecem ao longo do tempo e do espaço no continente apresentado no presente texto. Um destes exemplos está diretamente relacionado à Valfenda. Em Valfenda (Rivendell, na publicação original), Elrond (semi-elfo responsável por sua construção ainda na segunda era) se apresenta como um dos personagens importantes da saga do Anel e que se estabelece como um dos últimos recantos élficos da Terra-Média, estabelecendo-se como um lugar de conhecimento, força e resistência contra os despotismos que assolam a Terra-Média.

\footnotetext{
"Os elfos podem temer o Senhor do Escuro, e podem fugir de sua presença, mas nunca mais irão escutá-lo ou servi-lo. E aqui em Valfenda ainda vivem alguns dos maiores inimigos dele: os Sábios élficos, senhores de Eldar, de além dos mares mais distantes. Estes não temem os Espectros do Anel, pois os que moraram no Reino Abençoado vivem ao mesmo tempo nos dois mundos, e têm grande poder contra os Visíveis e os Invisíveis." (TOLKIEN, 2000, p.231).
} 
É importante a partir desta passagem quebrar a ideia de que o soberano (seja ele associado ao lado mau ou bom da história - ainda que refuto esta divisão binária pelos múltiplos interesses colocados em cada um dos grupos) esteja obrigatoriamente ligado à ideia de um ente maligno e que se estabelece como um inimigo da sociedade. Reafirmo aqui a importância de identificação das práticas culturais e societárias que configuram s diversos interesses destas mesmas sociedades e que se relacionam de diferentes maneiras para com os seus soberanos.

O Segundo Poder, ou como apontado por Ramos (2013), o Poder Disciplinar, apresenta-se como àquele que não está relacionado, diretamente, ao soberano, ou seja, existem representantes que fiscalizam e "mantêm a obediência" dos súditos. Estes representantes podem ser comparados a agentes do estado que regularizam e fiscalizam o território visando a manutenção da ordem estabelecida, fomentando também uma série de ações em benefício do soberano. "Na Terra-Média do mundo secundário, estes agentes são, por exemplo, os cavaleiros Nazgûl que, ordenados por Sauron, vagueiam pelas estradas do Shire em busca dos possuidores d'O Anel” (RAMOS, 2013, p.138). No caso destes instrumentos (Nazgûl) ainda se torna importante aventar a figura sobre o qual eles são descritos. Há aí uma clara referência ao símbolo da morte e à escuridão, tomada pela passagem a seguir.

Pela curva vinha um cavalo negro, não um pônei de hobbit, mas um cavalo grande: montado por um homem grande, que parecia abaixado na sela, envolto numa grande capa e num capuz preto, de modo que só se viam as botas nos estribos altos. O rosto, coberto por uma sombra, era invisível. Quando chegou à árvore onde estava Frodo, o cavalo parou. A figura do cavaleiro permanecia imóvel com a cabeça abaixada, como que tentando escutar algo. De dentro do capuz veio um ruído, como se alguém tentasse farejar um cheiro indefinível; a cabeça se virava para os dois lados da estrada. (...) Nesse momento o cavaleiro sentou- se ereto e sacudiu as rédeas. $\mathrm{O}$ cavalo avançou, primeiro andando devagar, para depois romper num trote rápido. Frodo se arrastou até a beira da estrada e ficou olhando o cavaleiro, até que desapareceu na distância. (TOLKIEN, 2000, p.77).

Estes, também instituem a prática do terror e da fiscalização com o intuito de manutenção de uma ordem vigente. A vigilância torna-se característica importante associada aos agentes, que, por sua vez, garantem que a soberania seja mantida. Verifica-se aqui, que os poderes (moderno e pré-moderno) se confundem, conforme 
também constatado pelo autor. Passam a existir diferentes estratégias que se interpõem de acordo com as necessidades daquele que detêm o poder. Ou seja, o poder soberano se instrumentaliza também a partir da disciplina e da capacidade de regulação sobre determinado território.

É curioso, no entanto, notar que a força passa a ser um recurso usado em diferentes momentos, seja orientada para a vilania, seja para a bondade dos heróis da história criada. Apesar de não poder ser rotulado como um soberano, tendo em vista sua ausência de súditos a comandar, Gandalf é diretamente responsável pelo "convencimento" do Rei Theóden, a partir da quebra de um feitiço que Língua de Cobra (Grima) lhe impusera. O discurso político e as inúmeras tentativas e tratativas políticas se apresentavam como ineficazes diante do quadro que se desenhara, sendo necessária a direta intervenção mágica (força) para que a prática política se estabelecesse.

Na escuridão, escutaram o chiado da voz de Língua de Cobra: - Não o aconselhei, senhor, a proibir esse cajado? Aquele tolo, Hama, nos traiu! - Houve um clarão como se um raio tivesse fendido o teto. Depois tudo ficou em silêncio. Língua de Cobra caiu esticado no chão. (TOLKIEN, 2000, p.538).

\section{4- Do uso irrestrito da força ao poder: a importância do Conselho de Elrond}

Conforme exposto anteriormente, verifica-se que o uso da força (seja ela atrelada à magia ou não no caso estudado) é algo recorrente no universo criado devido, inclusive, à inexistência do papel do Estado (moderno). Daí resulta-se um ambiente feudal e hostil no qual as diversas sociedades se desenvolvem ou fenecem. No entanto, torna-se importante aqui observar a utilização da força sob luzes bastante diferenciadas. De acordo com Dworkin (1999) existe uma grande diferença associada ao uso da força per se e a utilização da força associada ao cumprimento de uma obrigatoriedade específica.

[...] a legitimidade do poder de coerção do Estado está ligada ao conceito de obrigação política. Esta é assegurada, na maior parte das vezes, não pelo uso exclusivo da força física, mas pelo sentimento de se estar cumprindo obrigações genuínas. A adesão se daria mais facilmente ao se adotar a perspectiva do direito como integridade. (DWORKIN, 1999, p. 231). 
Deve-se observar que as obrigações genuínas, como exposto por Dworkin, no caso da Terra-Média e, particularmente, no período associado à narrativa do Senhor dos Anéis, não se estabelecem sob a luz de um Estado ou qualquer outro órgão regulamentador, mas sim sobre aquilo que une os chamados povos livres: o direito à escolha e à sobrevivência.

Sauron, ao utilizar de instrumentos regulatórios e fiscalizatórios, busca antes de qualquer coisa que se atinja o seu único objetivo: ter controle sobre o anel para governar sobre toda a Terra-Média. Estas ações são fundamentadas, basicamente, na dominação e coerção de sua própria figura. Fulgura aí a utilização do terror como pano de fundo para sobrepujar o adversário, podendo-se identificar o poder despótico em sua total resplandecência. Além disso, os representantes ainda se utilizavam de outras estratégias como a oferta de regalias e chantagens. Exemplo destas estratégias se estabelece quando Sauron, através de mensageiros buscando informações sobre o paradeiro do Um Anel, tenta se aliar aos anões, oferecendo à eles os três anéis que os antepassados da raça anã utilizavam e que há muito haviam caído nas mãos do Senhor do Escuro.

(...) um mensageiro veio até Dáin, mas não de Moria... de Mordor: um cavaleiro chegou à noite, chamando Dain até o portão. O Senhor Sauron, o Grande, dizia ele, desejava a nossa amizade. Em troca daria anéis, assim como tinha dado aos antigos. E o mensageiro queria muito saber a respeito de hobbits, de como eles eram, e onde morava. "Pois Sauron sabe", dizia ele, "que um deles foi conhecido de vocês em certa época" (TOLKIEN, 2000, p. 250)

O direito à vida e à liberdade, transformando aquilo que fora anteriormente discutido e definido anteriormente, condiciona inimigos históricos a unirem forças (como, por exemplo, elfos e anões) contra a tentativa de dominação daqueles que vem de fora. Ora, a figura do Conselho de Elrond e a tratativa política sobre o que fazer com o Um Anel, representa a articulação de forças em resposta ao poder saurônico. Elrond, ao tomar ciência das notícias advindas dos anões do norte, entre outras informações alertadas dentro do próprio Conselho. 
- Este é o propósito de todos terem sido chamados aqui. Chamados, eu digo, embora eu não tenha chamado vocês até mim, estrangeiros de terras distantes. Vocês vieram e estão aqui reunidos, neste exato momento, por acaso, como pode parecer. Mas não é assim. Acreditem que foi ordenado que nós, que estamos sentados, e ninguém mais, encontremos uma solução para o perigo do mundo. (TOLKIEN, 2000, p. 251)

Verifica-se aqui um momento em que a política se estabelece enquanto poder político (que se desenrola, a partir de mecanismos variados de convencimento). É exatamente aqui que em que podemos perceber um dos principais atos políticos da trama em estudo. Dussel (2007), descreve que a ação propriamente política se estabelece a partir do momento em que a mesma não vem da dominação ou do ato da força, mas sim da negociação de vontades e interesses. O autor, inclusive, apresenta a ideia de que esta ação política, aqui representada pelo Conselho de Elrond, não precisa sem inclusive baseada na unanimidade. Daí torna-se importante estabelecer que "o consenso, que une as vontades e ata o poder como força conjunta, pode ser alcançado, mas nunca de maneira perfeita (perfeição de acordos, seria novamente unanimidade)" (DUSSEL, 2007, p. 54).

É interessante notar, inclusive, que o próprio Conselho, retratado ao longo de mais de 50 páginas do livro A Sociedade do Anel, busca apresentar a imperfeição e as tensões provocadas pelas inúmeras possibilidades daquilo a se fazer com o Um Anel. Uma das discussões, por exemplo, refere-se à utilização ou não do artefato para servir às forças dos povos livres, ideia prontamente negada e refutada por Elrond e Gandalf.

Apesar de aqui não estarmos nos referindo à participação cidadã (ou seja, dos cidadãos de todos os povos livres), abre-se espaço, e daí, uma vez mais discutirmos a política a partir das ações que se desenrolam no universo estudado. O Conselho de Elrond apresenta uma perspectiva interessante quando da discussão acerca das representatividades na sua articulação política. E aí, devemos observar o Conselho pela ótica da Governança. No cenário construído não há qualquer espaço para a Governabilidade ser discutida como o nível de reconhecimento da sociedade civil (cidadãos dos povos livres) de entenderem e estabeleceram discussões acerca da qualidade dos agentes que os representam. O que está em jogo com a representação dos personagens é capacidade de articulação política frente ao que fazer a partir das situações vivenciadas por cada um dos povos diante das ameaças (diretas ou indiretas) advindas de Mordor. Apesar de serem independentes, observa-se a necessidade da interdependência entre os mesmos a partir de uma causa que os une. 
Quando se observa a tabela a seguir, por exemplo, verifica-se que os participantes do Conselho possuem diferentes motivações associadas à possibilidade da formação da Comitiva do Anel. Suas representações, por sua vez, estão atreladas a inúmeros laços culturais, políticos e ideológicos que convergem ao chamamento para tal momento, como é o caso das alianças pretéritas que se desenrolam em convites para participação de determinado evento ${ }^{5}$.

\begin{tabular}{|c|c|c|c|}
\hline Participantes & Raça & Representação & Assunto/Motivação \\
\hline $\begin{array}{l}\text { Frodo } \\
\text { Bolseiro }\end{array}$ & Hobbit & $\begin{array}{l}\text { Detentor temporário do Um } \\
\text { Anel }\end{array}$ & $\begin{array}{l}\text { Portador do Um } \\
\text { Anel }\end{array}$ \\
\hline Glóin & \multirow[t]{2}{*}{ Anão } & $\begin{array}{l}\text { Um dos anões da Cia. de } \\
\text { Thorin II Escudo de } \\
\text { Carvalho na busca para } \\
\text { recuperar Erebor }\end{array}$ & \multirow[t]{2}{*}{$\begin{array}{lr}\text { Ameaça } & \text { dos } \\
\text { mensageiros } & \text { de } \\
\text { Mordor } & \end{array}$} \\
\hline Gimli & & Filho de Gloin & \\
\hline Erestor & \multirow{5}{*}{ Elfo } & Elfo dos Portos Cincentos & $\begin{array}{l}\text { Representante dos } \\
\text { Primogêntos criados } \\
\text { pelos Valar. }\end{array}$ \\
\hline Galdor & & $\begin{array}{l}\text { Segundo senhor da Casa de } \\
\text { Hador }\end{array}$ & $\begin{array}{l}\text { Representante dos } \\
\text { Primogêntos criados } \\
\text { pelos Valar. }\end{array}$ \\
\hline Legolas & & $\begin{array}{l}\text { Filho de Thrandruil, Rei dos } \\
\text { Elfos do Norte da Floresta } \\
\text { das Trevas }\end{array}$ & \begin{tabular}{lr}
\multicolumn{2}{l}{ Representante } \\
elfos da & Floresta \\
indicado & por \\
Thrandruil &
\end{tabular} \\
\hline Elrond & & $\begin{array}{l}\text { Senhor de } \quad \text { Valfenda } \\
\text { (Rivendell) }\end{array}$ & $\begin{array}{lrr}\text { Líder de } & \text { Valfenda, } \\
\text { uma das últimas } \\
\text { fortalezas do } & \text { Reino } \\
\text { de Gil-Galad } & \end{array}$ \\
\hline Glorfindel & & $\begin{array}{l}\text { Senhor da Casa da Flor } \\
\text { Dourada em Gondolin }\end{array}$ & $\begin{array}{l}\text { Representante dos } \\
\text { Primogêntos criados } \\
\text { pelos Valar. }\end{array}$ \\
\hline Gandalf & $\begin{array}{l}\text { Maiar } \\
\text { (vive sob } \\
\text { forma } \\
\text { humana) }\end{array}$ & $\begin{array}{l}\text { Um dos espíritos primordiais. } \\
\text { Servo dos Valar. }\end{array}$ & $\begin{array}{l}\text { Conselheiro dos } \\
\text { homens e combater a } \\
\text { escuridão Auxílio na } \\
\text { construção } \\
\text { manutenção de Arda. }\end{array}$ \\
\hline Boromir & \multirow[b]{2}{*}{ Humano } & $\begin{array}{lcc}\begin{array}{l}\text { Filho de } \\
\text { governante } \\
\text { Gondor. }\end{array} & \begin{array}{c}\text { Denethor } \\
\text { Regente }\end{array} & \begin{array}{l}\text { II, } \\
\text { de }\end{array} \\
& & \\
\end{array}$ & $\begin{array}{lr}\text { Forças de } & \text { Mordor } \\
\text { ameaçam } & \text { Gondor. } \\
\text { Solicitação de ajuda }\end{array}$ \\
\hline Aragorn & & $\begin{array}{l}\text { Guardião do Norte - } \\
\text { Herdeiro de Isildur, Rei dos } \\
\text { Dúnedai }\end{array}$ & $\begin{array}{l}\text { Aliado de Gandalf e } \\
\text { relacionado com } \\
\text { Arwen, filha de } \\
\text { Elrond }\end{array}$ \\
\hline
\end{tabular}


Assim, a legitimidade democrática de cada um dos tais representantes (ora baseada em caso de hereditariedade ou no sangue - como é o caso de Boromir, Aragorn e Elrond por exemplo -, ora baseada nos laços de direito - como é o caso de Gloin, Gimli e Erastor) está relacionada à correlações políticas ou familiares que os tornam possíveis participantes daquele evento. Ora, não há discussão sobre qualquer qualidade destes representantes por meio do reconhecimento da sociedade civil ao qual eles representam. Isto se dá pelo fato de que neste ambiente não há ainda a formação de uma opinião pública (nas palavras de Dussel, 2007) que seja capaz de penetrar nas entranhas do campo político. Talvez, a exceção dos povos ali representados fossem os hobbits, que possuem uma arquitetura diferenciada de $\operatorname{poder}^{7}$, na qual a autonomia e liberdade concedida aos cidadãos diferem de outras sociedades representadas ao longo do livro.

Muitos outros exemplos podem e devem ser debatidos para orientar e consolidar a visão ampla da política e de poder associada à construção imaginada da Terra-Média. Inclusive, Ruane e James (2008), a partir da obra "The International Relations of Middle-earth Learning from The Lord of the Rings" fazem uma avaliação de como as relações internacionais podem se utilizar de maneira pedagógica das diversas interações existentes entre os povos descritos.

\section{5 - Considerações Finais}

Verifica-se, a partir das múltiplas leituras e relações levantadas (ainda que nem todas tivessem sido exploradas nas suas devidas profundidades) que o Senhor dos Anéis, obra ficcional, apresenta-se como uma obra que explora as estruturas e relações de poder que se estabelecem nas sociedades descritas. $\mathrm{O}$ paralelismo frente à Idade Média de nosso mundo, bem como a construção das estratégias e mecanismos de como este poder deve ser (re)negociado continuadamente (a partir de novas ou velhos instrumentos), corrobora para o entendimento da complexidade que se origina no real e se espelha no ficcional. Retratam e amalgamam, assim, uma série de acontecimentos, desejos e orientações políticas que são percebidas em um jogo contínuo de (re)construção da política. Serve, portanto, como um paralelo às relações estabelecidas em nosso mundo, no qual diversas forças atuam continuadamente para possibilitar a retomada de governos despóticos, institucionais e políticos. 
As representatividades e funções atreladas aos diversos grupos sociais pertencentes ao Conselho propiciaram a articulação e potencialidade da mudança, recaindo sobre a política uma resposta ao cenário que se estabelecia na Terra-Média, retratada a partir da dominação do Estado Absolutista frente aos chamados povos livres. O Conselho surge então como uma resposta, baseada na articulação política de diferentes interessados a ameaça que se estabelecia no Leste. A leitura destes fatos contribui sobremaneira para avaliar o contínuo embate que transportamos na discussão política desde Aristóteles até o tempo presente. A ficção, portanto, vive da realidade e vice-versa, ao passo que instrui e capacita percepções acerca de novas estratégias e correlações de poder. Ignorar o fantástico é ignorar, portanto, uma grande parcela das construções e possibilidades atreladas a nossa própria realidade.

Esta leitura possui, por sua vez, impacto preponderante sobre uma série de ciências que se utilizam do (universo) fantástico a fim de hipotetizar as relações humanas que repercutem e são construídas através da imaginação. Atentar para estes universos construídos abrem novas perspectivas para se pensar possibilidades, cenários e ações sobre o real.

\section{NOTAS}

* Mestre em Geografia pela Pontifícia Universidade Católica do Rio de Janeiro. Doutorando do Programa de Pós-Graduação em Geografia da PUC-Rio. Atualmente atua como Professor do quadro complementar no Departamento de Geografia da PUC-Rio lecionando as disciplinas de Cartografia, Geoprocessamento e Saneamento Ambiental. Também atua como professor pesquisador dos grupos de pesquisa GeTERJ (Grupo de Pesquisa Gestão Territorial no Estado do Rio de Janeiro), MorkoTektos e NEAC (Núcleos de Estudos em Ambientes Costeiros). E-mail para contato: rsngeo@hotmail.com

\footnotetext{
2 No qual a representatividade no governo de uma dado recorte político-administrativo deve ser costurada a partir dos anseios e vontades advindas da coletividade.

${ }^{3}$ Gollum, personagem que deteve o Um Anel antes de Bilbo Bolseiro foi capturado pelas forças de Sauron e conduzido à Barad-dûr. Neste local, foi torturado e interrogado com o intuito de entregar o referido Anel. Após as seguidas torturas, apresenta os nomes de "Bolseiro" e "Condado" como pistas para que se chegasse ao artefato.

${ }^{4}$ No entanto, é importante salientar que o autor reconhece, mais adiante em seu texto, que no caso do papel do Rei Theoden, apesar de ser colocado como soberano de seu reino, ele o faz sobre o véu enfeitiçado de Grima. Ou seja, o Rei Theoden se encontra sob encantamento instaurando a partir desta relação o discurso ideológico de Saruman. Desta maneira, o Rei apresenta-se como o "falso soberano" já que o discurso ideológico e as ações estão sendo comandadas na realidade por Saruman.

${ }_{5}^{5}$ Como exemplo, pode-se citar a confiança depositada em Aragorn por Gandalf para levar os hobbits da estalagem do Pônei Saltitante até Valfenda.

${ }^{6}$ Gil-Galad foi o Alto-Rei dos Noldor na Terra-Média durante a Segunda Era

$7 \mathrm{E}$ que merece ser discutida frente às arquiteturas de poder existentes na Terra Média.
} 


\section{REFERÊNCIAS BIBLIOGRÁFICAS}

BEAUDRY, CLAVAL, Paul. Espaço e Poder. Rio de Janeiro: Zahar Editores. 1978.

DWORKIN, Ronald. O império do Direito. São Paulo: Martins Fontes, 1999.

DUSSEL, Enrique. 20 Teses da Política. São Paulo: Expressão Popular / CLACSO, 2007.

FONT Joan. N; RUFÍ, Joan.V. A crise e a reestruturação do Estado-Nação. In: FONT Joan. N; RUFÍ, Joan.V. Geopolítica, Identidade e Globalização. São Paulo.: Annablume. 2006.

HABERMAS, Jürgen. Realizações e limites do Estado nacional europeu. In: BALAKRISHNAN, Gopal (Org.). Um mapa da questão nacional. Rio de Janeiro. Editora Contraponto: 2000.

HAMPTON, Jean. Hobbes and the Social Contract Tradition. Cambridge University Press., New York. 1995. Disponível em: <https://books.google.com.br/books?hl=ptBR\&lr=\&id=1M_LCgAAQBAJ\&oi=fnd\&pg $=$ PP $1 \& d q=$ Hobbes + Social + Contract\&ots $=$ qhLpxkGLaE\& sig=wMOcn_a7R3FnzlREKpqZVOyDoJU\#v=onepage\&q=Hobbes\%20Social\%20Contract\&f=false $>$. Acesso em: 29 abr. 2017

MORIN, Edgar. Cultura de massas do século XX: o espírito do tempo - Neurose. Rio de Janeiro: Forense-Universitário, 1984.

RAMOS, Hugo Felipe. O Panóptico de Sauron: Poder e Vigilância no Senhor dos Anéis de J.R.R. Tolkien. Observatório. Lisboa, v. 7, n. 3, jun. 2013.

Disponível em:

$<$ http://www.scielo.mec.pt/scielo.php?script=sci_arttext\&pid=S1646-59542013000300008>. Acesso em: 19 out. 2017

ROUSSEAU, Jean Jacques. Do Contrato Social. Coleção Pensadores, São Paulo, 1973.

RUANE, Abigail. E; JAMES, Patrick. The International Relations of Middle-earth. Learning from The Lord of the Rings. International Studies Perspectives. Oxford. n.9, 2008, v. 9, n.4, nov. 2008, p. 377-394.

WEBER, Max. Ensaios de Sociologia. Ed. Guanabara: Rio de Janeiro, 1981.

TOLKIEN, J. R. R. O Senhor dos Anéis. Tradução de. Lenita Maria Rímoli Esteves. São Paulo: Martins Fontes, 2000.

TOLKIEN GATEWAY. Languages. Disponível em: <http://tolkiengateway.net/wiki/Languages>. Acesso em: 22 out. 2017. 


\section{LECTURAS DEL PODER EN LA TERCERA ERA DE LA TIERRA-MEDIA: UN ENSAYO BASADO EN EL SEÑOR}

DE LOS ANILLOS

RESUMEN: EL IMAGINARIO SE ESTABLECE COMO CAMPO FÉRTIL PARA EL PENSAMIENTO DE LAS MÚLTIPLES RELACIONES EXISTENTES Y EXPERIMENTADAS POR LA REALIDAD HUMANA. LAS CUESTIONES ASOCIADAS A LA DISCUSIÓN SOCIOECONÓMICA, FÍSICA, BIÓTICA, POLITICA Y OTRAS PUEDEN SER EXPLORADAS POR CONSTRUCCIONES QUE POSEEN, POR BASE, LA IMAGINACIÓN. EN ESTE CASO, LA LITERATURA SURGE COMO UNO DE LOS INSTRUMENTOS DE REPRESENTACIÓN DE REALIDADES (DES)CONOCIDAS PASIBLES DE SER LEÍDAS BAJO MÚLTIPLES ÓPTICAS. LA OBRA DE J. R. R. TOLKIEN TITULADA "EL SEÑOR DE LOS ANILLOS" SE PRESENTA COMO UN ARQUETIPO DE LA IMAGINACIÓN COMPLEJA EN LA QUE DIFERENTES SOCIEDADES SE PRESENTAN, RELACIONÁNDOSE INTERNA Y EXTERNAMENTE DE MÚLTIPLES MANERAS. LA OBRA LITERARIA, A PARTIR DE SU PROPIA COMPLEJIDAD, SE PRESENTA COMO EXCELENTE ESCENARIO PARA EL DESARROLLO DE INNUMERABLES ENSAYOS SOBRE DIVERSAS ESFERAS QUE INVOLUCRAN LA PROPIA PERCEPCIÓN HUMANA DE LA REALIDAD. UNA DE LAS ESFERAS MÁS DISCUTIDAS EN LA OBRA DE TOLKIEN SE REFIERE A LA DINÁMICA DEL PODER OBSERVADA EN LA POLIITICA ENTRE LAS MÚLTIPLES SOCIEDADES DE LA TIERRA-MEDIA. EN ESTE SENTIDO, LOS OBJETIVOS DEL PRESENTE ESTUDIO SON ANALIZAR CÓMO EL PODER ES ENTENDIDO POR SUS MÚLTIPLES PERSONAJES (Y SOCIEDADES) Y CÓMO SU DINÁMICA POSIBILITÓ EL SURGIMIENTO DE LA POLÍTICA EN LA TIERRA-MEDIA.

PALABRAS CLAVE: SEÑOR DE LOS ANILLOS, PODER, POLÍTICA, SOBERANÍA

READINGS OF POWER IN THE THIRD ERA OF THE MIDDLE-EARTH: A TEST BASED ON THE LORD OF THE RINGS

ABSTRACT: THE IMAGINARY ESTABLISHES ITSELF AS A FERTILE FIELD FOR THINKING ON THE MULTIPLE RELATIONS THAR EXIST AND ARE EXPERIENCED THROUGH THE HUMAN REALITY. ISSUES RELATED TO THE SOCIOECONOMIC, PHYSICAL, BIOTIC AND POLITICAL DISCUSSIONS, AMONG OTHERS, CAN BE EXPLORED FROM A STRUCTURE GROUNDED ON THE IMAGINATION. IN THIS CASE, LITERATURE APPEARS AS AN INSTRUMENT OF REPRESENTATION OF (UN)KNOWN REALITIES THAT CAN BE READ FROM SEVERAL PERSPECTIVES, AS MENTIONED ABOVE. THE WORK OF J. R. R. TOLKIEN ENTITLED "THE LORD OF THE RINGS" PRESENTS ITSELF AS AN ARCHETYPE OF COMPLEX IMAGINATION IN WHICH DIFFERENT SOCIETIES ARE PRESENTED AS HAVING INTERNAL AND EXTERNAL RELATIONS AMONG THEMSELVES. THIS WORK, FROM ITS OWN COMPLEXITY, PRESENTS ITSELF AS AN EXCELLENT STAGE FOR THE DEVELOPMENT OF EXPERIENCES ON THE DIFFERENT SPHERES THAT COMPOSE THE HUMAN REALITY. FURTHER INFORMATION IN TOLKIEN'S WORK REFERS TO THE DYNAMICS OF POWER THAT MAY BE AN INDICATOR OF POLICY AMONG THOSE EXISTING IN MIDDLE-EARTH. IN THIS SENSE, THE OBJECTIVE OF THE PRESENT STUDY IS TO ANALYSE, FROM THE REALIZED WORK, HOW THE POWER IS FACED BY ITS MULTIPLE CHARACTERS (AND SOCIETIES), AS WELL AS UNDERSTAND WHICH DYNAMIC ALLOWED FOR THE RISE OF POLITICAL POWER IN MIDDLE-EARTH.

KEYWORDS: LORD OF THE RINGS, POWER, POLITICS, SOVEREIGNTY 